\title{
Meta-analysis: Association between hepatitis B virus preS mutation and hepatocellular carcinoma risk
}

\author{
Citrawati Dyah Kencono Wungu ${ }^{1,2}$ (D) | Fis Citra Ariyanto ${ }^{3,4}$ (D) | \\ Gwenny Ichsan Prabowo $^{1}$ | Soetjipto Soetjipto ${ }^{1,2}$ (D) | Retno Handajani,
}

\author{
${ }^{1}$ Department of Medical Biochemistry, \\ Faculty of Medicine, Universitas Airlangga, \\ Surabaya, Indonesia \\ ${ }^{2}$ Institute of Tropical Disease, Universitas \\ Airlangga, Surabaya, Indonesia \\ ${ }^{3}$ Faculty of Nursing, Jember University, \\ Jember, Indonesia \\ ${ }^{4}$ Hearing Vision Ltd-Darmo General \\ Hospital, Surabaya, Indonesia

\section{Correspondence} \\ Citrawati Dyah Kencono Wungu, \\ Department of Medical Biochemistry, \\ Faculty of Medicine, Universitas Airlangga, \\ Surabaya, Indonesia. \\ Email: citrawati.dyah@fk.unair.ac.id \\ Funding information \\ Tahir Professorship Program, Grant/Award \\ Number: -
}

\begin{abstract}
Previous observational studies suggested that hepatitis B virus (HBV) preS mutation plays an important role in the existence of HBV-related hepatocellular carcinoma (HCC). However, the results are still debatable. With an increasing number of studies about this topic, this study employed a meta-analysis to identify the association between HBV preS mutation and HCC risk. We searched for eligible studies from PubMed, ProQuest, CINAHL, ScienceDirect and Springer databases to assess the association between HBV mutation and HCC risk. This meta-analysis was conducted using RevMan 5.3 to provide pooled estimate for odds ratio (ORs) with $95 \%$ confidence intervals $(95 \% \mathrm{Cls})$. Twenty-one clinical studies were included in this metaanalysis study which consisted of 1738 participants with HBV-related HCC and 3740 $\mathrm{HBsAg}$-positive patients without HCC. All studies used samples of Asian population. PreS deletion was the most common mutation found in all studies. We found that ORs of $\mathrm{HBV}$ overall preS deletion was associated with $\mathrm{HCC}(\mathrm{OR}=3.28 ; 95 \% \mathrm{Cl}=2.32$ 4.65; $P<.00001$; random-effects model). Each preS1 and preS2 deletion was associated with increased risk of HCC, with OR $2.42(95 \% \mathrm{Cl}=1.25-4.68, P=.008)$ and $3.36(95 \% \mathrm{Cl}=2.04-5.55, P<.00001)$, respectively. PreS2 start codon mutation was also significantly associated with $\mathrm{HCC}$ risk $(\mathrm{OR}=2.47 ; 95 \% \mathrm{Cl}$ : $1.15-5.27 ; P=.02$; random-effect model). The result of this meta-analysis suggested that HBV preS deletion (all, preS1 and preS2) and preS2 start codon mutation might contribute to the increased risk of HBV-related HCC.
\end{abstract}

\section{KEYWORDS}

hepatitis B virus, hepatocellular carcinoma, meta-analysis, preS mutation

\section{1 | INTRODUCTION}

Hepatitis B virus (HBV) infection is an infection targeting the liver which can cause both acute and chronic diseases. HBV infection is easily transmitted through blood and body fluid, while the virus can survive outside the body for up to 7 days. ${ }^{1,2}$ HBV infection is the most dangerous type of hepatitis virus infection and ranks fifteenth as the leading cause of death worldwide. It is estimated that around 887000 people die each year due to HBV infection, mainly by liver cirrhosis or hepatocellular carcinoma $(\mathrm{HCC})^{3}$ 
There are several factors influencing the clinical course of HBV infection into $\mathrm{HCC}$, including mutations in the preS region of $\mathrm{HBV} .{ }^{4-6}$ Some studies reported associations between mutations in the HBV preS region and $\mathrm{HCC} .^{7-10}$ The preS region consists of preS1 and preS2 domain. It is a highly immunogenic region of HBV which has many epitopes for $\mathrm{B}$ and T lymphocytes. ${ }^{11}$ PreS region also has many other functional sites that play an important role in the attachment, replication and progression of viral infections. ${ }^{12}$

Mutations in important functional sites of the preS regions can cause imbalance in the synthesis of HBV surface protein. For example, mutation in the $\mathrm{L}$ protein start codon, $\mathrm{S}$ promoter, viral topology domain, nucleocapsid binding region, $\mathrm{CBF}$ binding region, and $\mathrm{pHSA}$ binding region can cause $\mathrm{L}$ protein to be synthesized more than $S$ and $M$ proteins are thus detected in endoplasmic reticulum (ER). ${ }^{13,14}$ Excessive accumulation of $L$ protein in ER leads to ER stress and trigger oxidative stress. The reactive oxygen species formed can trigger hepatocarcinogenesis through the activation of vascular endothelial growth factor/Akt/mammalian target of rapamycin (VEGF/Akt/mTOR), calpain cleavage, and nuclear factor (NF)-кB pathway. ${ }^{15,16}$

However, data on HBV preS mutations and HCC progression show different results in each population. In the last decade, much more studies (both case-control and cohort studies) focusing on the association between preS mutations and HCC have emerged which do not only focus on pres deletion mutation but other important preS mutation such as preS2 start codon mutation as well. Thus, it would be important in discerning the contribution of each mutation in preS region for HCC risk through analysing their effects, respectively. This is an updated meta-analysis to give us a more comprehensive understanding on those mutations with $\mathrm{HCC}$ risk, especially in the area where HBV infection is prevalent.

\section{2 | MATERIALS AND METHODS}

\section{1 | Study selection}

A comprehensive literature search was conducted to search journals in the latest decade using the following databases: PubMed, ProQuest, CINAHL, ScienceDirect and Springer until 30 November 2019. This study used Medical Subject Heading (MeSH) terms with the following keywords: 'hepatitis b virus' or 'HBV' and 'preS' and 'mutation' or 'variant' and 'hepatocellular carcinoma' or 'HCC'. In addition, the researchers performed a manual search to retrieve potential articles without missing any additional eligible studies.

\subsection{Criteria for article screening}

The eligible studies should meet the following criteria: (a) the article assessed the association between HBV preS mutations and HCC; (b) the study design was case-control or cohort; and (c) odds ratio with the $95 \%$ confidence interval was reported or could be determined through available data.

The unpublished reports such as conference abstracts were not included. This study excluded articles with patients who have co-infection with HCV and/or HIV, patients with occult HBV infection, duplicated data, or any article with sufficient information. Studies written by the same author focusing on distinct mutations or different samples were still included.

\subsection{Exclusion criteria}

The excluded literatures were as follows: (a) cross-sectional study, case report or series, experimental, editorial and narrative review; (b) duplicated publication; (c) studies with indefinite population recruited or unqualified data; and (d) non-English articles.

\section{4 | Quality assessment}

The quality of the studies had been evaluated using the guidelines for reporting observational studies for infectious diseases, developed by strengthening the reporting of molecular epidemiology for infectious diseases (STROME-ID), which was built based on strengthening the reporting of observational studies in epidemiology (STROBE) statement. The use of this guideline was to improve and standardize the reporting of infectious-disease molecular data in epidemiological research. We checked whether the included studies fulfilled the points in the STROME-ID checklist. ${ }^{17}$

\section{5 | Data collection}

The data were collected by two members (CDKW and FCA) independently, using the standardized form. The researchers consulted with other investigators in case of any disagreement until reaching the consensus. The following information was extracted: first author's name, publication year, country, study design, matched variables, sequencing method, number of cases (patients who have developed $\mathrm{HCC}$ ) and controls (patients without HCC), genotype distribution, mutation sites, and the corresponding ORs and 95\% Cls.

\subsection{Statistical analysis}

The mutation's impact on HCC was estimated by the summary of odds ratios (ORs) and their corresponding $95 \% \mathrm{Cl}$. The overall effect was appraised through the $Z$ test which could be considered significant if the $P$ value $<.05$. Heterogeneity was assessed with the Q-statistic test and $I^{2}$ test. The $I^{2}$ statistic measured the percentage of total variation across the studies due to clinical or methodological heterogeneity rather than chance. The pool estimated ORs were measured with models based on fixed effects or random effects 
assumptions. If the value of $I^{2}$ statistics was $<50 \%$ or the $P$ value was more than .1, the fixed-effects model could be applied; otherwise, random effects model would be used. Begg's funnel plot was performed to determine any publication bias. All the statistical analyses were performed using Review Manager version 5.3 (The Cochrane Collaboration).

\section{3 | RESULTS}

\section{1 | Study characteristics}

As seen in Figure 1, we initially obtained 4871 studies through primary database searching and 21 through manual searching. Then, we selected 530 potentially relevant articles. Moreover, we removed the duplicates and screened the studies, and 26 of them were excluded due to non-English language. Eventually, as much as 233 fulltext studies were checked for their eligibility. Finally, some studies were excluded due to irrelevant study design and insufficient information or unqualified articles.

Eventually, a total of 21 potential articles were screened and met the STROME recommendations. Those articles collected 5518 HBV-infected participants in accumulation, which consisted of 1738 HCC cases and 3740 controls. The basic characteristics of all included studies and patients were shown in Table 1 . The papers were published between 2007 and 2016. The sample size for each study ranged from 40 to 1820. Of the 21 included studies, eight studies took samples of Chinese population, $8,18-24$ four studies took Taiwanese, ${ }^{9,25-27}$ four were South Korean, ${ }^{10,28-30}$ two were Hong Kongese, ${ }^{12,31}$ one was Indonesian, ${ }^{32}$ one was Thai, ${ }^{33}$ and one from mixed four Asian countries (Vietnamese, Korean, Taiwanese, Japanese). ${ }^{34}$ The characteristics of the included studies in this meta-analysis are shown in Table 1.

The most commonly reported type of preS mutation was preS deletion, which was dominated by preS2 deletion and followed by preS1 deletion. Most of these studies stated that HBV preS deletions were clustered mainly in the $3^{\prime}$ end of preS1 and 5 ' end of pres2 regions. Most of the deletions are in-frame deletion with multiplication of 3. PreS2 start codon mutation was also found in several included studies. The reported HBV genotype was dominated by genotypes $C$ and $B$, while genotype $D$ was reported in 1 study. Genotype $C$ was the most reported by studies that took population in East Asia, while genotype B was most commonly found in a study conducted in Indonesia, which is a part of Southeast Asia region.

\subsection{PreS deletion and HCC risk}

PreS deletion mutation was the most common preS mutation found in all included studies. This study found a statistically significant association between preS deletion and HCC risk (Figure 2). There was

FIGURE 1 PRISMA diagram of the literature search

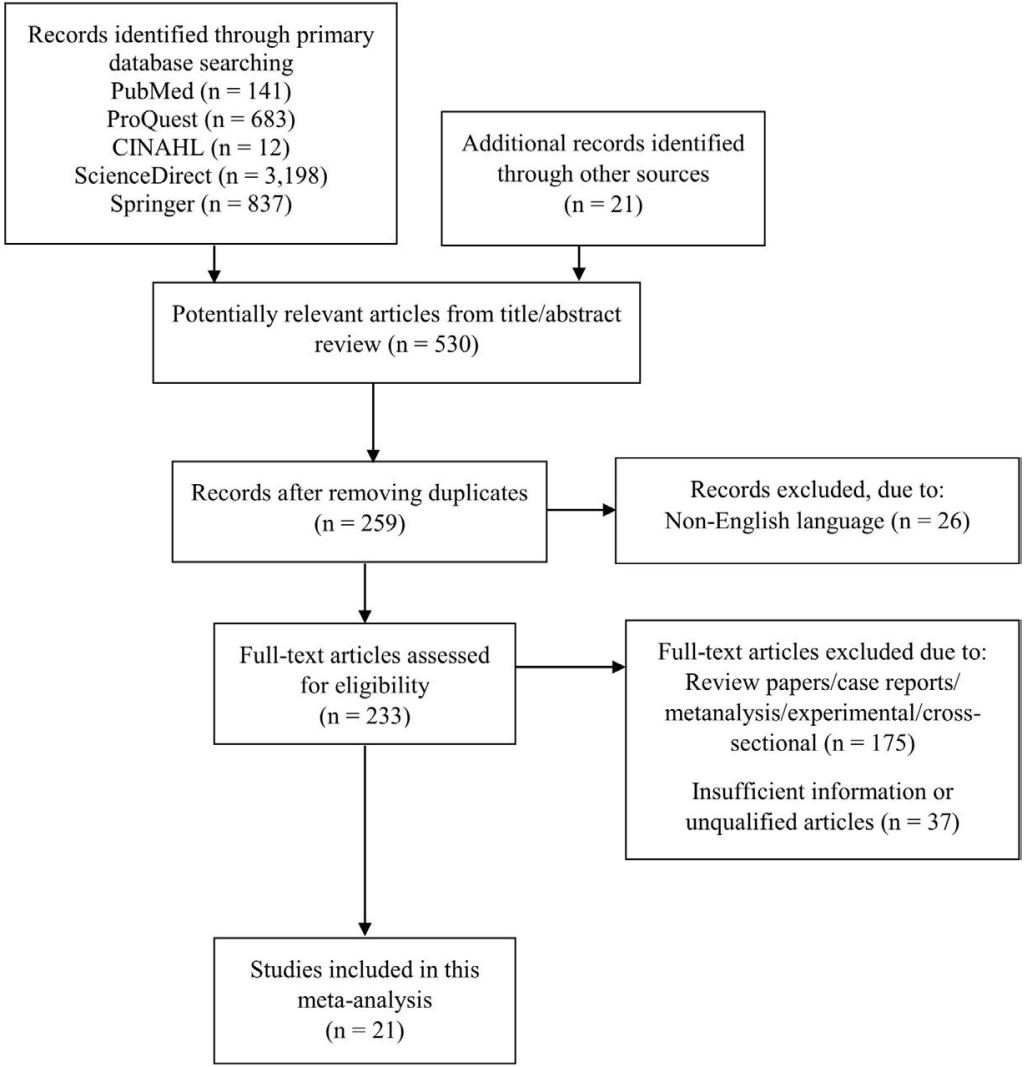


TABLE 1 Characteristics of included studies in this meta-analysis

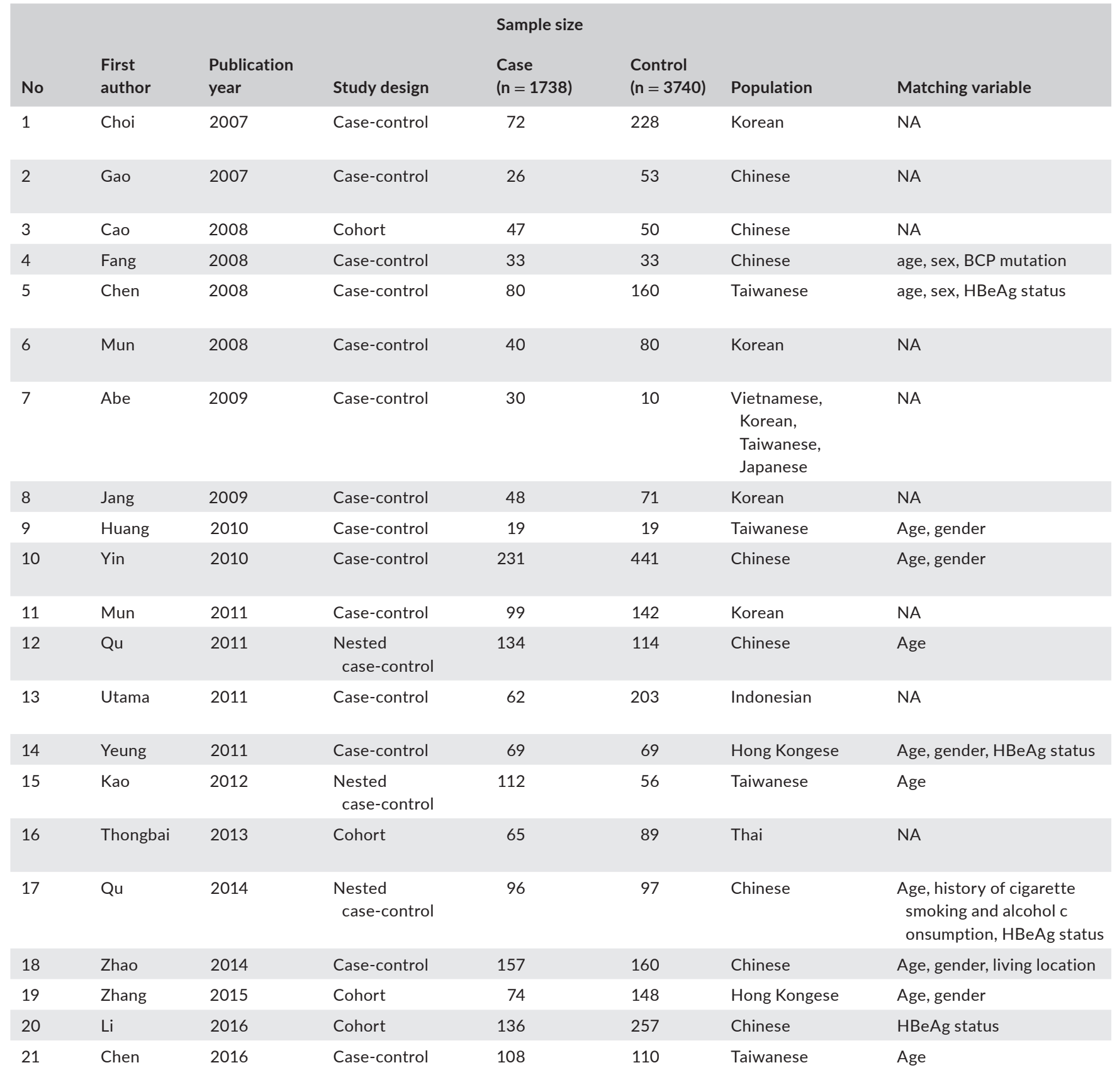

Abbreviations: ASC, asymptomatic carrier; $\mathrm{CH}$, chronic hepatitis; HCC, Hepatocellular Carcinoma, LC, liver cirrhosis.

a significant heterogeneity $\left(P<.00001, I^{2}=77 \%\right.$ ); thus, the random-effects model was used for analysis. The forest plot showed that subject with HCC had more HBV preS deletions than subject without HCC (35.16\% vs $11.11 \%)$. The overall risk estimates OR for $\mathrm{HCC}$ of pres deletion was $3.28(95 \% \mathrm{Cl}=2.32-4.65, \mathrm{P}<.00001)$ in a random-effects model. As heterogeneity was found in the statistical analyses, we analysed publication bias by Funnel plot to evaluate the sources of heterogeneity. We found that heterogeneity between studies was mainly caused by the studies by Yin et $\mathrm{al}^{18}$ and Chen et $\mathrm{al}^{27}$ as after these studies were excluded, no significant heterogeneity was found. Genotype $\mathrm{C}$ with preS mutation had significant association with HCC risk, with OR for HCC of preS deletion with genotype $C$ was $3.53(95 \% \mathrm{Cl}=2.64-4.73, P<.00001)$ in a fixed-effect model (Figure 3).

\section{3 | PreS1 deletion and $\mathrm{HCC}$ risk}

Some study separated preS1 and preS2 deletions from all preS mutation. We analysed each preS1 and preS2 deletion and found a statistically significant association between preS1 deletion and $\mathrm{HCC}$ risk (Figure 4). There was a significant heterogeneity $\left(P=.0003, I^{2}=71 \%\right)$; 


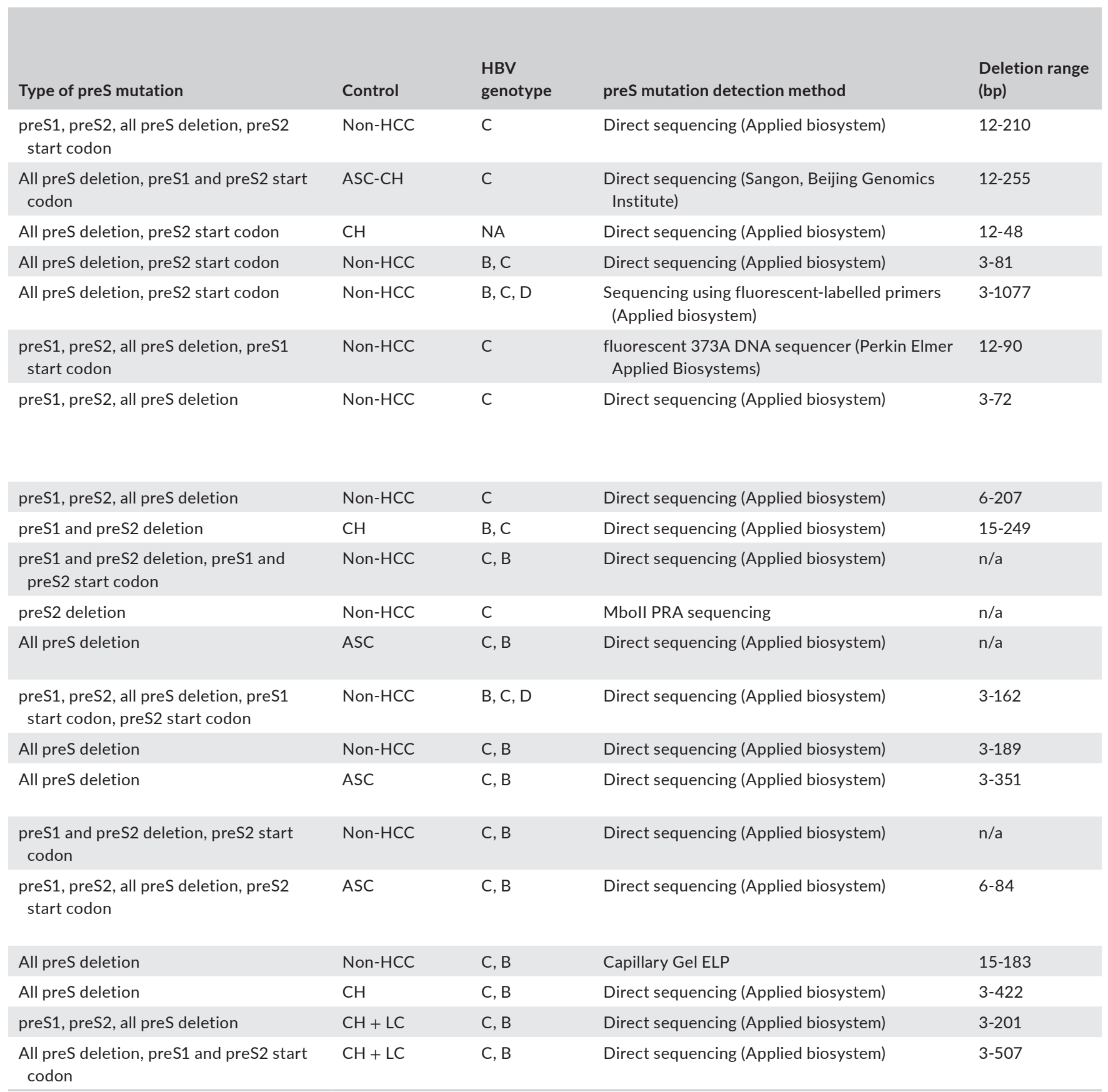

thus, the random-effects model was used for analysis. The overall risk estimates OR for HCC of preS1 deletion was $2.42(95 \% \mathrm{Cl}=1.25-4.68$, $P=.008)$. As heterogeneity was found in the statistical analyses, we analysed publication bias by Funnel plot to evaluate the sources of heterogeneity. We found that heterogeneity between studies was mainly caused by the studies by Yin et al, ${ }^{18}$ as after this study was excluded, no significant heterogeneity was found. Both genotypes $B$ and $C$ showed significant association between preS1 deletion and $\mathrm{HCC}$ risk, with OR for genotype $C$ was $2.87(95 \% \mathrm{Cl}=1.47-5.61, P=.002$, random-effect model) and $\mathrm{OR}$ for genotype $\mathrm{B}$ was $2.83(95 \% \mathrm{Cl}=1.17-6.84, P=.002$, fixed-effect model; Figure 5).

\subsection{PreS2 deletion and $\mathrm{HCC}$ risk}

We also found a statistically significant association between preS2 deletion and $\mathrm{HCC}$ risk (Figure 6). There was a significant heterogeneity $\left(P=.0002, I^{2}=71 \%\right)$; thus, the random-effects model was used for analysis. The overall risk estimates OR for HCC of preS2 deletion was $3.36(95 \% \mathrm{Cl}=2.04-5.55, P<.00001)$. As heterogeneity was found in the statistical analyses, we analysed publication bias by Funnel plot to evaluate the sources of heterogeneity. We found that heterogeneity between studies was mainly caused by the studies by Yin et al, ${ }^{18}$ as after this study was excluded, no significant 
heterogeneity was found. Both genotypes $B$ and $C$ showed significant association between preS2 deletion and $\mathrm{HCC}$ risk, with OR for genotype $C$ was 3.18 (95\% Cl = 1.85-5.48, $P<.00001$, random-effect model) and OR for genotype B was $6.82(95 \% \mathrm{Cl}=1.18-39.41$, $P=.03$, random-effect model; Figure 7).

\section{5 | PreS1 start codon mutation and HCC risk}

In this meta-analysis, we obtained non-significant association between preS1 start codon mutation and $\mathrm{HCC}$ risk $(P=.15$, randomeffect model). Both genotypes $C$ and $B$ also showed non-significant association between preS1 start codon mutation and HCC risk.

\section{6 | PreS2 start codon mutation and HCC risk}

PreS2 start codon mutation was either an amino acid substitution from methionine (M120) to other amino acids or in a form of deletion. In this meta-analysis, all HCC subjects in the included studies had more preS2 start codon mutation than those without HCC (21.2\% vs $4.96 \%)$. As shown in Figure 8 , this study observed a statistically significant association between preS2 start codon mutation and $\mathrm{HCC}$ risk $(\mathrm{OR}=2.47 ; 95 \% \mathrm{Cl}=1.15-5.27, \mathrm{P}=.02$, random-effect model). As heterogeneity was found in the statistical analyses, we analysed publication bias by Funnel plot to evaluate the sources of heterogeneity. We found that heterogeneity between studies was mainly caused by the studies by $Y$ in et al, ${ }^{18}$ as after this study was

\begin{tabular}{|c|c|c|c|c|c|c|c|}
\hline \multirow[b]{2}{*}{ Study or Subgroup } & \multicolumn{2}{|c|}{ HCC } & \multicolumn{2}{|c|}{ Control } & \multicolumn{3}{|c|}{ Odds Ratio } \\
\hline & Events & Total & Events & Total & Weight & M-H, Random, $95 \% \mathrm{Cl}$ & Year \\
\hline Gao 2007 & 10 & 26 & 3 & 53 & $3.2 \%$ & $10.42[2.55,42.57]$ & 2007 \\
\hline Choi 2007 & 31 & 72 & 41 & 228 & $5.8 \%$ & $3.45[1.94,6.14]$ & 2007 \\
\hline Mun 2008 & 21 & 40 & 16 & 80 & $5.0 \%$ & $4.42[1.93,10.12]$ & 2008 \\
\hline Chen 2008 & 28 & 80 & 27 & 160 & $5.7 \%$ & $2.65[1.43,4.92]$ & 2008 \\
\hline Fang 2008 & 15 & 33 & 6 & 33 & $4.0 \%$ & $3.75[1.22,11.48]$ & 2008 \\
\hline Cao 2008 & 24 & 47 & 9 & 50 & $4.7 \%$ & $4.75[1.89,11.94]$ & 2008 \\
\hline Jang 2009 & 17 & 48 & 13 & 71 & $4.9 \%$ & $2.45[1.05,5.69]$ & 2009 \\
\hline Abe 2009 & 27 & 30 & 0 & 10 & $1.1 \%$ & $165.00[7.84,3474.63]$ & 2009 \\
\hline Yin 2010 & 41 & 231 & 34 & 1589 & $6.1 \%$ & $9.87[6.11,15.93]$ & 2010 \\
\hline Huang 2010 & 8 & 19 & 0 & 19 & $1.2 \%$ & $28.83[1.52,547.34]$ & 2010 \\
\hline Yeung 2011 & 23 & 69 & 11 & 69 & $5.0 \%$ & $2.64[1.17,5.96]$ & 2011 \\
\hline Utama 2011 & 11 & 62 & 21 & 205 & $5.1 \%$ & $1.89[0.86,4.18]$ & 2011 \\
\hline Mun 2011 & 35 & 99 & 19 & 142 & $5.6 \%$ & $3.54[1.88,6.68]$ & 2011 \\
\hline Qu 2011 & 32 & 134 & 14 & 114 & $5.5 \%$ & $2.24[1.13,4.45]$ & 2011 \\
\hline Kao 2012 & 56 & 112 & 4 & 56 & $4.1 \%$ & $13.00[4.40,38.37]$ & 2012 \\
\hline Thongbai 2013 & 6 & 65 & 9 & 89 & $4.1 \%$ & $0.90[0.31,2.68]$ & 2013 \\
\hline Qu 2014 & 28 & 96 & 11 & 97 & $5.2 \%$ & $3.22[1.50,6.93]$ & 2014 \\
\hline Zhao 2014 & 74 & 157 & 45 & 160 & $6.2 \%$ & $2.28[1.43,3.63]$ & 201 \\
\hline Zhang 2015 & 22 & 74 & 14 & 148 & $5.3 \%$ & $4.05[1.93,8.51]$ & 201 \\
\hline Chen 2016 & 55 & 108 & 67 & 110 & $5.9 \%$ & $0.67[0.39,1.14]$ & 201 \\
\hline Li 2016 & 47 & 136 & 52 & 257 & $6.2 \%$ & $2.08[1.31,3.32]$ & 201 \\
\hline Total $(95 \% \mathrm{CI})$ & & 1738 & & 3740 & $100.0 \%$ & $3.28[2.32,4.65]$ & \\
\hline Total events & 611 & & 416 & & & & \\
\hline
\end{tabular}

FIGURE 2 Forest plot for the correlation between preS deletion and HCC risk Study or Subgroup Events Total Events

\begin{tabular}{|c|c|c|c|c|c|}
\hline Choi 2007 & 31 & 72 & 41 & 228 & $24.2 \%$ \\
\hline Fang 2008 & 14 & 29 & 5 & 30 & $5.5 \%$ \\
\hline Gao 2007 & 10 & 26 & 3 & 53 & $2.6 \%$ \\
\hline Jang 2009 & 17 & 48 & 13 & 71 & $14.6 \%$ \\
\hline Mun 2008 & 21 & 40 & 16 & 80 & $10.9 \%$ \\
\hline Mun 2011 & 35 & 99 & 19 & 142 & $21.8 \%$ \\
\hline Qu 2014 & 24 & 89 & 9 & 92 & $13.9 \%$ \\
\hline Utama 2011 & 3 & 12 & 11 & 54 & $6.5 \%$ \\
\hline Total $(95 \% \mathrm{Cl})$ & \multicolumn{3}{|c|}{415} & 750 & $100.0 \%$ \\
\hline Total events & 155 & & 117 & & \\
\hline \multicolumn{6}{|c|}{ Heterogeneity: $\mathrm{Chi}^{2}=5.28, \mathrm{df}=7(\mathrm{P}=0.63) ; \mathrm{I}^{2}=0 \%$} \\
\hline
\end{tabular}

Odds Ratio

M-H, Fixed, $95 \% \mathrm{Cl}$

$3.45[1.94,6.14]$

$4.67[1.40,15.57]$

$10.42[2.55,42.57]$

$2.45[1.05,5.69]$

$4.42[1.93,10.12]$

$3.54[1.88,6.68]$

$3.41[1.48,7.82]$

$1.30[0.30,5.64]$

$3.53[2.64,4.73]$
Odds Ratio

M-H, Random, $95 \% \mathrm{Cl}$

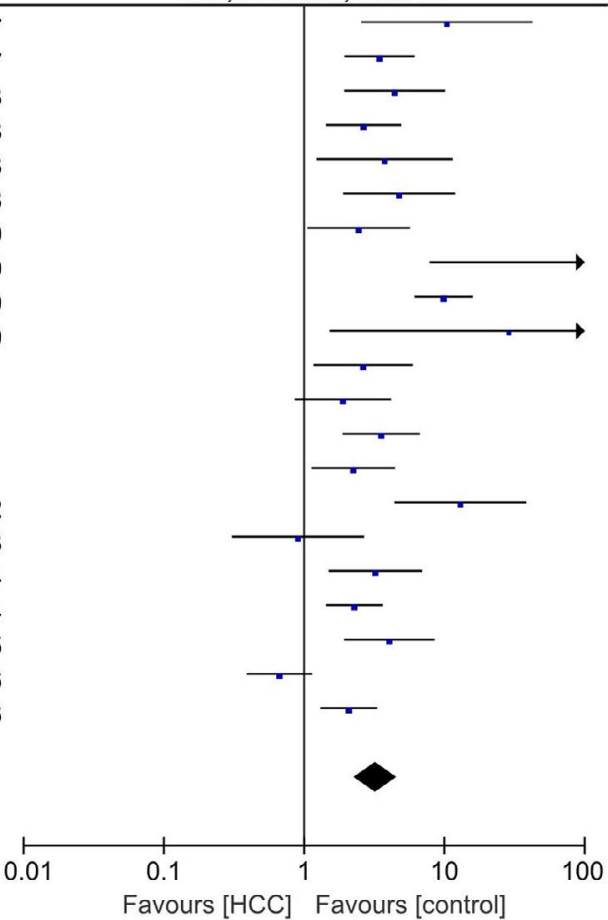


excluded, no significant heterogeneity was found. Genotype B with preS2 start codon mutation had significant association with $\mathrm{HCC}$ risk, with OR was $2.48(95 \% \mathrm{Cl}=1.17-5.26, P=.002)$ in a fixed-effect model (Figure 9).

\section{7 | Sensitivity analysis}

In this meta-analysis, there was no significant change in ORs by deleting a particular study, which indicated that no single study influenced the statistical significance of the overall results.

\section{4 | DISCUSSIONS}

The preS region of HBV consists of preS1 and preS2 regions which encodes three surface proteins that are structurally different but interrelated with each other: Large (L), medium (M), and small (S) proteins. ${ }^{35}$ The preS region also has $\mathrm{B}$ and $\mathrm{T}$ epitopes with other several functional domains [10]. Mutations in the preS region associated with HCC are usually in the form of deletions, although there are several studies showing that point mutations in the form of substitutions in some codons also play a contribution in HCC risk. $^{18,31,36}$

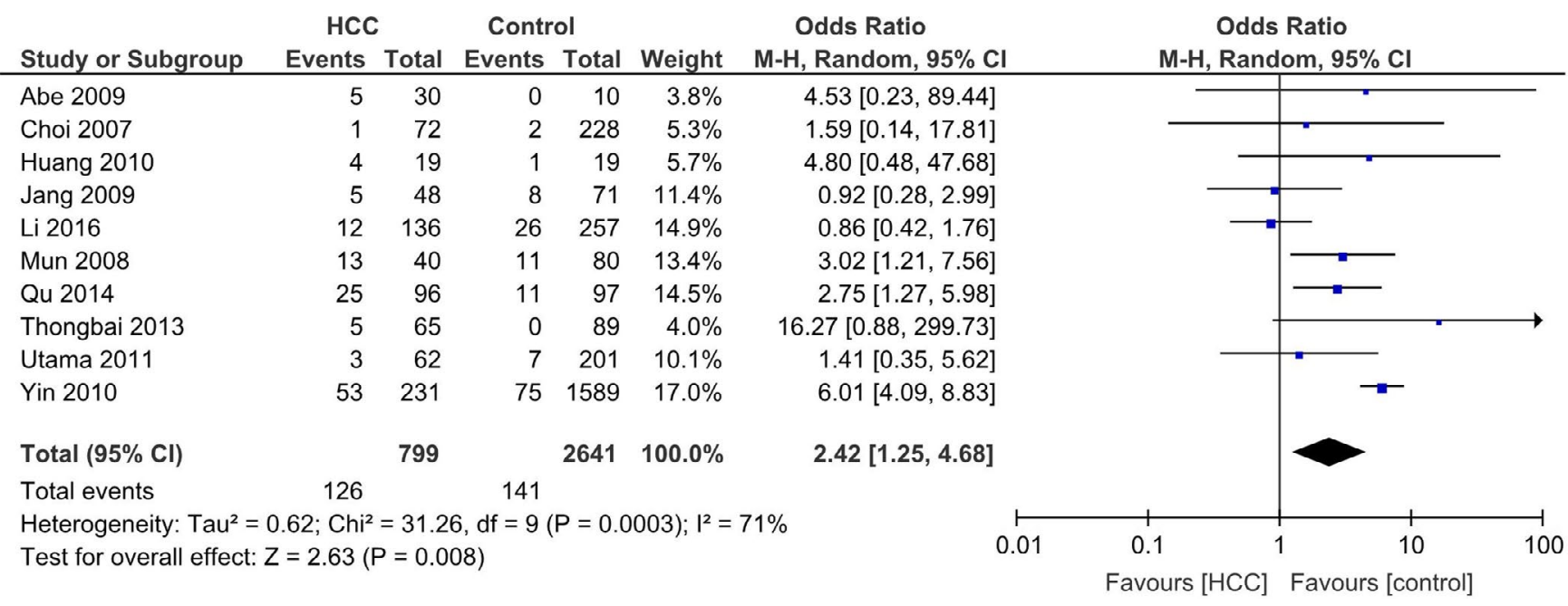

FIGURE 4 Forest plot for the correlation between preS1 deletion and HCC risk

(A)

\begin{tabular}{lrrrrr} 
& \multicolumn{6}{c}{ HCC } & \multicolumn{3}{c}{ Control } \\
Study or Subgroup & Events & Total & Events & Total & Weight \\
\hline Choi 2007 & 1 & 72 & 2 & 228 & $6.3 \%$ \\
Jang 2009 & 5 & 48 & 8 & 71 & $16.5 \%$ \\
Mun 2008 & 13 & 40 & 11 & 80 & $20.8 \%$ \\
Qu 2014 & 24 & 89 & 9 & 92 & $22.3 \%$ \\
Utama 2011 & 0 & 12 & 2 & 54 & $4.1 \%$ \\
Yin 2010 & 48 & 210 & 58 & 1254 & $30.0 \%$ \\
& & & & & \\
Total (95\% Cl) & & 471 & & 1779 & $100.0 \%$ \\
Total events & 91 & & 90 & &
\end{tabular}

Heterogeneity: $\mathrm{Tau}^{2}=0.35 ; \mathrm{Chi}^{2}=12.18, \mathrm{df}=5(\mathrm{P}=0.03) ; \mathrm{I}^{2}=59 \%$

Test for overall effect: $Z=3.08(P=0.002)$

Odds Ratio M-H, Random, 95\% Cl $1.59[0.14,17.81]$ $0.92[0.28,2.99]$ $3.02[1.21,7.56]$ $3.41[1.48,7.82]$ $0.84[0.04,18.62]$ $6.11[4.03,9.26]$ $2.87[1.47,5.61]$

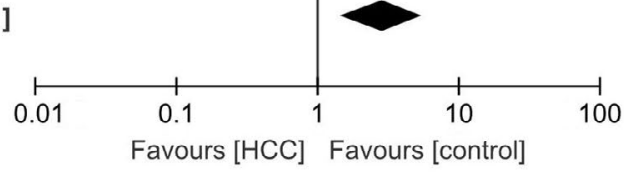

(B)

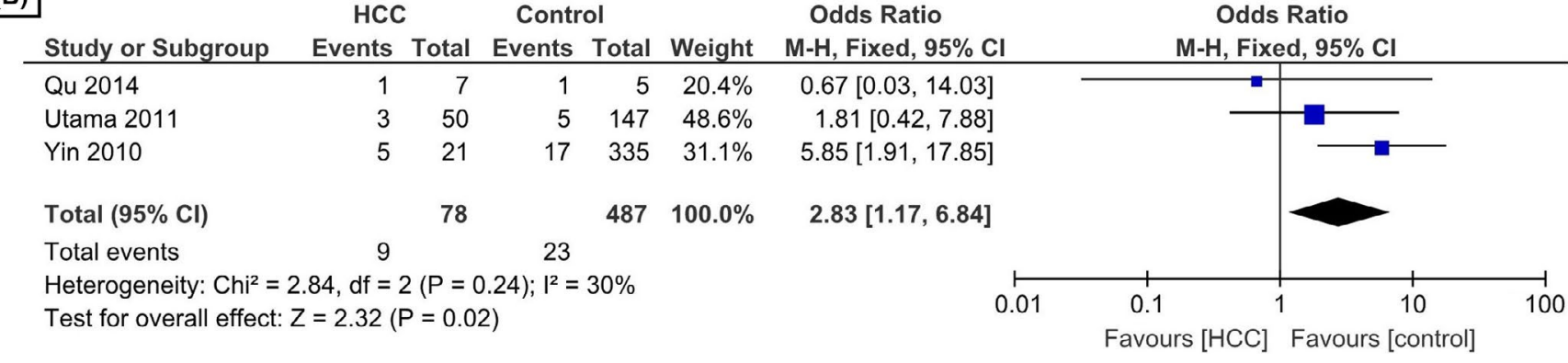

FIGURE 5 Forest plot for the correlation between preS1 deletion and HCC risk in genotype C (A) and B (B) 


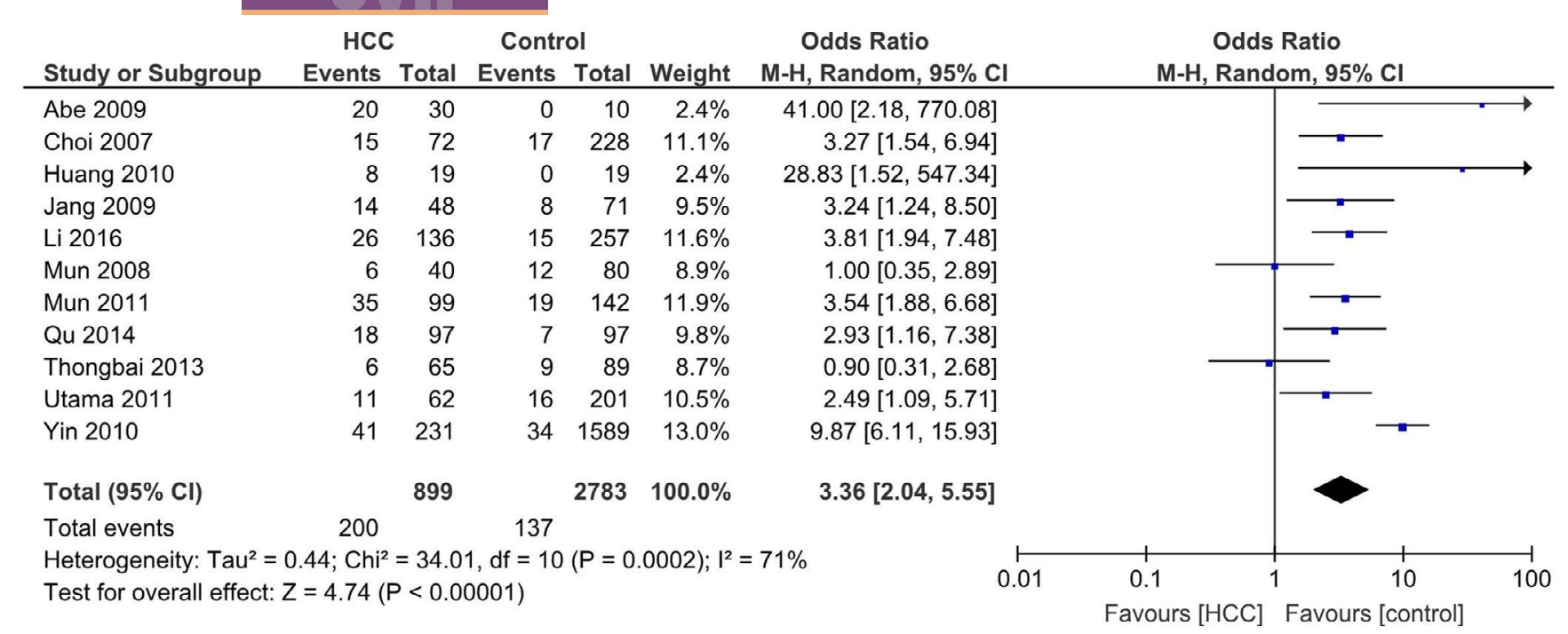

FIGURE 6 Forest plot for the correlation between preS2 deletion and HCC risk

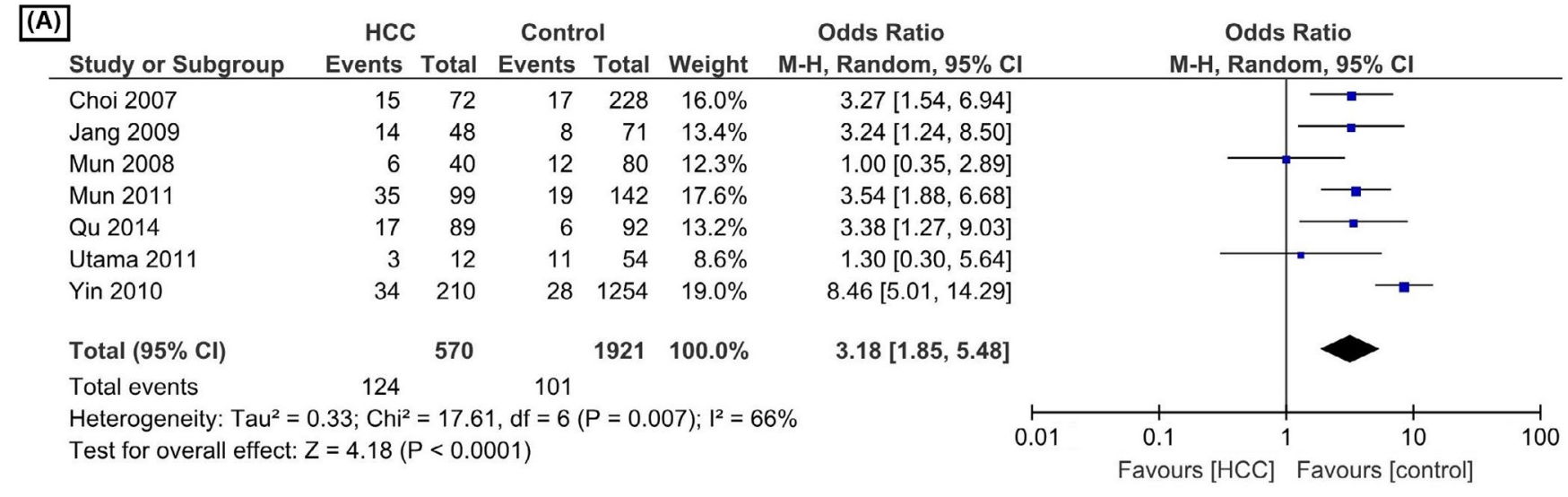

(B)

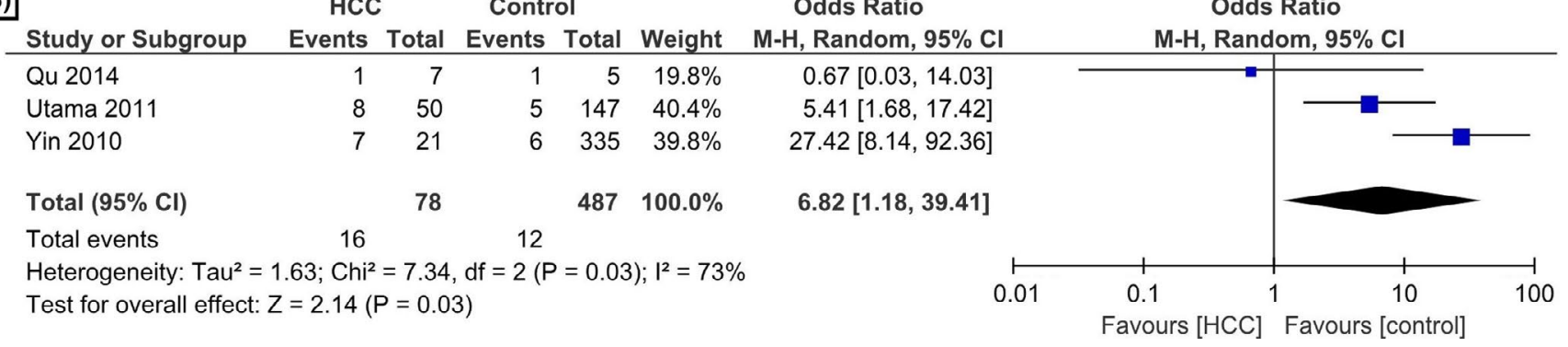

FIGURE 7 Forest plot for the correlation between preS2 deletion and HCC risk in genotype C (A) and B (B)

In mutations on preS1 functional sites, for example at the start of the preS1 codon and topology domain, excessive expression of $\mathrm{L}$ protein occurs. Mutations in the S promoter, the domain of viral secretion, the nucleocapsid binding domain and the CBF binding region can decrease the expression of $\mathrm{S}$ protein. Mutations in pHSA binding region and preS2 start codon can reduce the expression of $M$ protein and produce truncated $M$ protein. Furthermore, there will be a change in the ratio of $\mathrm{L}, \mathrm{M}$ and $\mathrm{S}$ protein expression. ${ }^{13,25,37}$ The large size of $L$ protein (up to $800 \mathrm{~nm}$ ) and its branched structure make this protein difficult to be secreted as normally, as the $L$ protein must form complexes with S and $\mathrm{M}$ proteins to be secreted. The low ratio of $S$ protein and defects in $M$ protein causes increasing $L$ protein accumulation inside the ER that leads to oxidative stress and further liver damage. ${ }^{38,39}$

In the absence of very large individual studies and limited ethnicity data, this study had carried out this updated meta-analysis for clarifying the correlation between HBV preS mutation and $\mathrm{HCC}$ risk. The largest sample size available in the individual study was 1820 subjects. All subject population in this meta-analysis were only Asians, and no study involving non-Asian participant was found. 
HCC Control Odds Ratio

Study or Subgroup

Cao 2008

Chen 2008

Chen 2016

Choi 2007

Fang 2008

Gao 2007

Qu 2014

Thongbai 2013

Utama 2011

Yin 2010

Total $(95 \% \mathrm{Cl})$

Total events

Heterogeneity: $\mathrm{Tau}^{2}=1.22 ; \mathrm{Chi}^{2}=65.73, \mathrm{df}=9(\mathrm{P}<0.00001) ; \mathrm{I}^{2}=86 \%$
Test for overall effect: $Z=2.33(\mathrm{P}=0.02)$

$44 \quad 1589-11.8 \%$
Odds Ratio Odds Ratio

Events Total Events Total Weight M-H, Random, 95\% Cl

$\begin{array}{llllll}10 & 47 & 4 & 50 & 9.2 \% & 3.11[0.90,10.72]\end{array}$

$\begin{array}{llllll}23 & 80 & 24 & 160 & 11.2 \% & 2.29[1.19,4.38]\end{array}$

$\begin{array}{lllll}24 & 40 & 24 & 46 & 10.6 \%\end{array}$

$\begin{array}{lllll}7 & 72 & 22 & 228 & 10.5 \%\end{array}$

$\begin{array}{lllll}10 & 33 & 6 & 33 & 9.5 \%\end{array}$

$\begin{array}{lllll}6 & 26 & 4 & 53 & 8.8 \%\end{array}$

$\begin{array}{lllll}17 & 96 & 7 & 97 & 10.3 \%\end{array}$

$\begin{array}{lllll}6 & 65 & 5 & 89 & 9.3 \%\end{array}$

362

$69 \quad 231$

$1.38[0.58,3.24]$

$1.01[0.41,2.47]$

$1.96[0.62,6.21]$

$3.67[0.94,14.43]$

$2.77[1.09,7.02]$

$1.71[0.50,5.86]$

$1.23[0.32,4.77]$

$14.96[9.91,22.57]$

$2.47[1.15,5.27]$

FIGURE 8 Forest plot for the correlation between preS2 start codon mutation and HCC risk

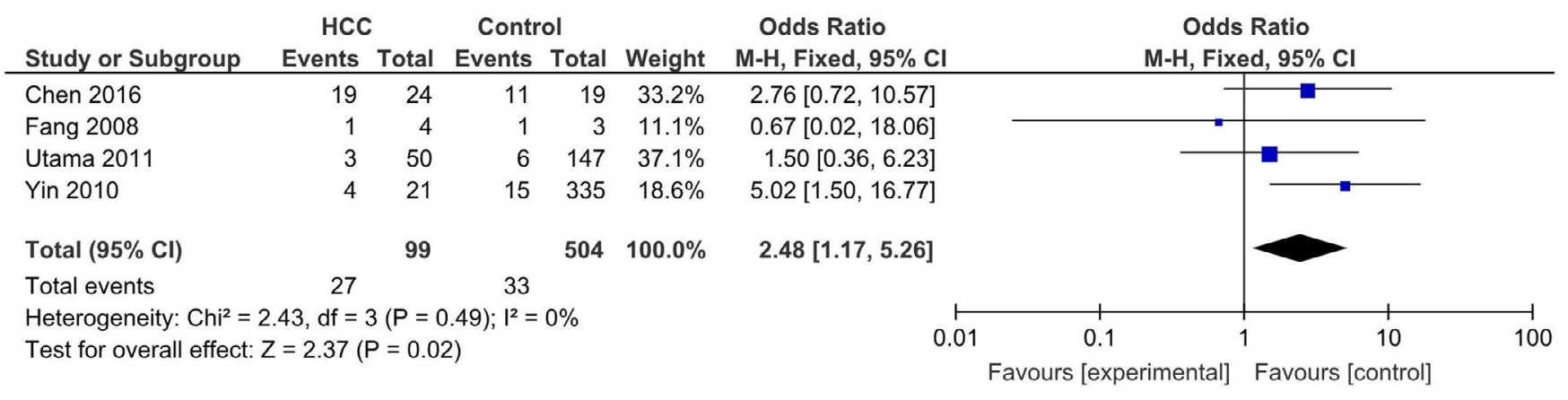

FIGURE 9 Forest plot for the correlation between preS2 start codon mutation and HCC risk in genotype B

Asian countries are reported to have a high or high-intermediate prevalence of HBV infection in general population, in which the infections in this region are most prevalent during infancy or childhood. ${ }^{40}$ The high prevalence of HBV infection in Asian populations also causes high risk of HCC incidence. ${ }^{41}$ Meanwhile, the ethnicities obtained in this study were mostly Chinese. In this meta-analysis, genotype $\mathrm{C}$ was the most common genotype of $\mathrm{HBV}$ in the included studies due to majority samples of East Asian population (mostly Chinese), in which genotype $C$ is mostly found in the area. ${ }^{42}$ The least common genotype was genotype $B$, except in one study from Indonesia in which genotype B was prevalent. ${ }^{32,43}$

This study managed to identify the association between preS mutation with HCC risk in this meta-analysis. The results showed that all preS deletion, preS1 deletion, preS2 deletion and preS2 start codon mutation had a significant correlation with the increased risk of HCC. The pooled crude ORs from the included studies suggested that all pres deletions were associated with 3.28 increased risk of $\mathrm{HCC}(95 \% \mathrm{Cl}=2.32-4.65, P<.00001)$ in a random-effects model, compared with HBV infection without HCC. While the pooled crude ORs from the included studies suggested that both preS1 and preS2 deletions were associated with increased risk of $\mathrm{HCC}$, with OR $2.42(95 \% \mathrm{Cl}=1.25-4.68, P=.008)$ and $3.36(95 \% \mathrm{Cl}=2.04-$ $5.55, P<.00001)$, respectively. In this meta-analysis, we found no significant association between preS1 start codon mutation and $\mathrm{HCC}$ risk. We found that preS2 start codon mutation was significantly associated with $\mathrm{HCC}$ risk, with $\mathrm{OR}=2.47(95 \% \mathrm{Cl}=1.15-5.27$, $P=.02$, random-effect model).

In the genotype analysis, preS deletion was significantly associated with $\mathrm{HCC}$ in genotype $\mathrm{C}$, preS1 and preS2 in both genotypes $\mathrm{B}$ and $\mathrm{C}$, and preS2 start codon in genotype B. However, this should be more elucidated in the future, as data regarding the association between preS mutation and HBV genotype are still lacking. As most included studies came from Asian countries, we did not find genotypes other than B and C for further analysis. Some mutations carry both preS1 deletion and preS2 deletion which generally harbour extensive deletion. This condition seems unable to make either the large or middle surface protein, although the major surface ORF is intact. ${ }^{24}$ This kind of deletion also removes all or part of a critical epitope in preS1 and/or preS2. Most of the deletion regions encompassed T-cell and B-cell epitopes and important functional sites. ${ }^{5}$ Some studies stated that in genotype B, deletion mutation tends to occur in preS1 or preS1/S2 region, while in genotype $\mathrm{C}$, the deletion mutation usually occurs in the preS2 region. ${ }^{25,32}$

Although many observational studies had been conducted, there are still few meta-analysis studies that identify the relationship between preS mutations and HCC. The results of this meta-analysis 
are in line with the meta-analysis conducted by Wang et al which showed a significant relationship between preS deletion and HCC risk in Asian populations; however, the meta-analysis did not analyse the effect of different preS1 and preS2 region on HCC risk. The study also did not analyse the association between preS1 and preS2 start codon mutations with $\mathrm{HCC}$ and did not distinguish the genotype of HBV. ${ }^{4}$

This research proved the role of preS deletion and preS2 start codon mutation on the risk of HCC. However, it did not rule out the influence of other factors that also play a role in the incidence of HCC. This is because the pathogenesis of HCC due to HBV infection is also influenced by age, gender, mutations in other susceptible genes ( $\mathrm{X}$, precore/core region), and host genetic polymorphism. These factors should be considered in any studies involving the role of pres mutation on HCC.

Another limitation of this study is that this meta-analysis only included a limited number of eligible studies, particularly available ethnicity. This study found no research taking samples from outside Asia. Although Asia is a highly endemic area of HBV infection, another hyperendemic region such as Africa should also affect the outcome. In conclusion, this study revealed that HBV preS mutation is associated with increased risk of HCC, especially in Asian countries.

\section{ACKNOWLEDGEMENTS}

We give thanks to Dato' Sri Prof. Dr Tahir for supporting this research through the Tahir Professorship Program, Indonesia.

\section{CONFLICT OF INTEREST}

Citrawati Dyah Kencono Wungu, Fis Citra Ariyanto, Gwenny Ichsan Prabowo, Soetjipto and Retno Handajani declare that they have no conflict of interest.

\section{ORCID}

Citrawati Dyah Kencono Wungu iD https://orcid.

org/0000-0001-5180-957X

Fis Citra Ariyanto iD https://orcid.org/0000-0001-6883-195X

Soetjipto Soetjipto (iD https://orcid.org/0000-0003-2203-5565

\section{REFERENCES}

1. Sarkar N, Chakravarty R. Hepatitis B virus infection, MicroRNAs and liver disease. Int J Mol Sci. 2015;16(8):17746-17762.

2. Center for Disease Control and Prevention. Hepatitis B Questions and Answers for the Public. https://www.cdc.gov/hepatitis/hbv/ bfaq.htm.Published2019. Accessed December 3, 2019.

3. World Health Organization. Hepatitis B. https://www.who. int/news-room/fact-sheets/detail/hepatitis-b. Published 2019. Accessed December 1, 2019.

4. Xie JX, Zhao J, Yin JH, et al. Association of novel mutations and heplotypes in the preS region of hepatitis $B$ virus with hepatocellular carcinoma. Front Med China. 2010;4(4):419-429.

5. Chen BF. Hepatitis B virus pre-S/S variants in liver diseases. World J Gastroenterol. 2018;24(14):1507-1520.

6. An P, Xu J, Yu Y, Winkler CA. Host and Viral genetic variation in HBV-related hepatocellular carcinoma. Front Genet. 2018;9:1-15.

7. Chen BF, Liu CJ, Jow GM, Chen PJ, Kao JH, Chen DS. High prevalence and mapping of pre-S deletion in hepatitis $B$ virus carriers with progressive liver diseases. Gastroenterology. 2006;130(4):1153-1168.

8. Gao ZY, Li T, Wang J, et al. Mutations in preS genes of genotype C hepatitis B virus in patients with chronic hepatitis B and hepatocellular carcinoma. J Gastroenterol. 2007;42(9):761-768.

9. Chen $\mathrm{C}-\mathrm{H}$, Changchien $\mathrm{C}-\mathrm{S}$, Lee $\mathrm{C}-\mathrm{M}$, et al. Combined mutations in pre-s/surface and core promoter/precore regions of hepatitis B virus increase the risk of hepatocellular carcinoma: a case-control study. J Infect Dis. 2008;198(11):1634-1642.

10. Mun H-S, Lee S-A, Kim H, Hwang E-S, Kook Y-H, Kim B-J. Novel F141L pre-S2 mutation in hepatitis b virus increases the risk of hepatocellular carcinoma in patients with chronic genotype $C$ infections. J Virol. 2011;85(1):123-132.

11. Shouval D, Roggendorf H, Roggendorf M. Enhanced immune response to hepatitis $B$ vaccination through immunization with a PreS1/Pre-S2/S Vaccine. Med Microbiol Immunol. 2015;204(1):57-68.

12. Zhang AY, Lai CL, Huang FY, et al. Evolutionary changes of hepatitis $B$ virus Pre-S mutations prior to development of hepatocellular carcinoma. PLoS One. 2015;10(9):1-14.

13. Chen B-F. Clinical significance of the hepatitis B virus Pre-S deletion. FJJM. 2010;85-95.

14. Su I-J, Wang LH-C, Hsieh W-C, et al. The emerging role of hepatitis $B$ virus Pre-S2 deletion mutant proteins in HBV tumorigenesis. J Biomed Sci. 2014;21(1):98.

15. Pollicino T, Cacciola I, Saffioti F, Raimondo G. Hepatitis B virus PreS/S gene variants: pathobiology and clinical implications. J Hepatol. 2014;61(2):408-417.

16. Li YW, Yang FC, Lu HQ, Zhang JS. Hepatocellular carcinoma and hepatitis B surface protein. World J Gastroenterol. 2016;22(6):1943-1952.

17. Field N, Cohen T, Struelens MJ, et al. Strengthening the reporting of molecular epidemiology for infectious diseases (STROME-ID): an extension of the STROBE statement. Lancet Infect Dis. 2014;14(4):341-352.

18. Yin J, Xie J, Zhang H, et al. Significant association of different preS mutations with hepatitis B-related cirrhosis or hepatocellular carcinoma. J Gastroenterol. 2010;45(10):1063-1071.

19. Qu LS, Liu TT, Jin F, et al. Combined pre-S deletion and core promoter mutations related to hepatocellular carcinoma: a nested case-control study in China. Hepatol Res. 2011;41(1):54-63.

20. Qu LS, Liu JX, Liu TT, et al. Association of hepatitis B virus pre-S deletions with the development of hepatocellular carcinoma in Qidong, China. PLoS One. 2014;9(5):1-8.

21. Zhao ZM, Jin $Y$, Gan $Y$, et al. Novel approach to identifying the hepatitis $B$ virus pre-S deletions associated with hepatocellular carcinoma. World J Gastroenterol. 2014;20(37):13573-13581.

22. Li X, Qin $Y$, Liu $Y$, et al. PreS deletion profiles of hepatitis B virus (HBV) are associated with clinical presentations of chronic HBV infection. J Clin Virol. 2016;82:27-32.

23. Cao Z, Bai X, Guo X, Jin Y, Qian G, Tu H. High prevalence of hepatitis $B$ virus pre-S mutation and its association with hepatocellular carcinoma in Qidong, China. Arch Virol. 2008;153(10):1807-1812.

24. Fang ZL, Sabin CA, Dong BQ, et al. Hepatitis B virus pre-S deletion mutations are a risk factor for hepatocellular carcinoma: a matched nested case - Control study. J Gen Virol. 2008;89(11):2882-2890.

25. Huang H-P, Hsu H-Y, Chen C-L, et al. Pre-S2 deletions of hepatitis $\mathrm{B}$ virus and hepatocellular carcinoma in children. Pediatr Res. 2010;67(1):90-94.

26. Kao JH, Liu CJ, Jow GM, Chen PJ, Chen DS, Chen BF. Fine mapping of hepatitis $B$ virus pre-S deletion and its association with hepatocellular carcinoma. Liver Int. 2012;32(9):1373-1381.

27. Chen BF. Different pre-S deletion patterns and their association with hepatitis B virus genotypes. World J Gastroenterol. 2016;22(35):8041-8049. 
28. Mun H-S, Lee S-A, Jee $\mathrm{Y}$, et al. The prevalence of hepatitis B virus preS deletions occurring naturally in korean patients infected chronically with genotype C. J Med Virol. 2008;80:1189-1194.

29. Jang JS, Kim HS, Kim HJ, et al. Association of concurrent hepatitis B surface antigen and antibody to hepatitis B surface antigen with hepatocellular carcinoma in chronic hepatitis B virus infection. J Med Virol. 2009;81:1531-1538.

30. Choi MS, Kim DY, Lee DH, et al. Clinical significance of pre-S mutations in patients with genotype $C$ hepatitis $B$ virus infection. J Viral Hepat. 2007;14(3):161-168.

31. Yeung $\mathrm{P}$, Wong $\mathrm{DKH}$, Lai CL, Fung J, Seto WK, Yuen MF. Association of hepatitis $B$ virus pre-S deletions with the development of hepatocellular carcinoma in chronic hepatitis B. J Infect Dis. 2011;203(5):646-654.

32. Utama A, Siburian MD, Fanany I, et al. Low prevalence of hepatitis B virus pre-S deletion mutation in Indonesia. J Med Virol. 2011;83:1717-1726.

33. Thongbai C, Sa-nguanmoo $P$, Kranokpiruk $P$, Poovorawan $K$, Poovorawan $\mathrm{Y}$, Tangkijvanich $\mathrm{P}$. Hepatitis $\mathrm{B}$ virus genetic variation and TP53 R249S mutation in patients with hepatocellular carcinoma in Thailand. Asian Pacific J Cancer Prev. 2013;14(6):3555-3559.

34. Abe K, Thung SN, Wu HC, et al. Pre-S2 deletion mutants of hepatitis $B$ virus could have an important role in hepatocarcinogenesis in Asian children. Cancer Sci. 2009;100(12):2249-2254.

35. Tong S, Li J, Wands JR, Wen YM. Hepatitis B virus genetic variants: Biological properties and clinical implications. Emerg Microbes Infect. 2013;2(1):1-11.

36. Liu WC, Wu IC, Lee YC, et al. Hepatocellular carcinoma-associated single-nucleotide variants and deletions identified by the use of genome-wide high-throughput analysis of hepatitis B virus. J Pathol. 2017;243(2):176-192.
37. Ogura S, Tameda M, Sugimoto K, et al. A substitution in the pre-S1 promoter region is associated with the viral regulation of hepatitis B virus. Virol J. 2019;16(1):1-11.

38. Bruss V. Hepatitis B virus morphogenesis. World J Gastroenterol. 2007;13(1):65-73.

39. Churin Y, Roderfeld M, Roeb E. Hepatitis B virus large surface protein: function and fame. Hepatobiliary Surg Nutr. 2015;4(1):1-10.

40. Shan S, Cui F, Jia J. How to control highly endemic hepatitis B in Asia. Liver Int. 2017;2018(38):122-125.

41. El-Serag HB. Epidemiology of viral hepatitis and hepatocellular carcinoma. Gastroenterology. 2012;142(6):1264-1273.e1.

42. Lin SYC, Magalis BR, Salemi M, Liu HF. Origin and dissemination of hepatitis $B$ virus genotype $C$ in East Asia revealed by phylodynamic analysis and historical correlates. J Viral Hepat. 2019;26(1):145-154.

43. Yano Y, Utsumi T, Lusida MI, Hayashi Y. Hepatitis B virus infection in Indonesia. World J Gastroenterol. 2015;21(38):10714-10720.

44. Wang C, Teng Z, Zhu Y, Zhao AZ, Sun C. Associations between pre-S deletion mutation of hepatitis $B$ virus and risk of hepatocellular carcinoma in the Asian population: a meta-analysis. Med Sci Monit. 2015;21:1072-1077.

How to cite this article: Wungu CDK, Ariyanto FC, Prabowo GI, Soetjipto S, Handajani R. Meta-analysis: Association between hepatitis $B$ virus preS mutation and hepatocellular carcinoma risk. J. Viral Hepat.. 2020;00:1-11. https://doi. org/10.1111/jvh.13402 